Martin Guillermo Ramirez

https://doi.org/10.32976/stratfuz.2021.37

\title{
Gyula Ocskay (ed.) (2020): 15 years of the EGTCs. Lessons learnt and future perspectives. Central European Services for Cross-Border Initiatives, Budapest
}

For someone who has followed European developments on cross-border cooperation (CBC) for more than two decades, it has been a pleasure going through this book, with an excellent selection of authors who are well-known and authorised voices on $\mathrm{CBC}$, its instruments and policies. I have marked plenty of pages for a deeper reading and future advice. There are also very interesting maps and tables, but something has particularly drawn my attention throughout the whole book: its specific approach towards the future, offering very valuable clues about the meaning of EGTCs for the future development of cross-border cooperation. Most chapters of this book were most probably finished during the pandemic, as well as its edition and its presentation (finally online during the Border Forum in Paris on 9-10 November 2020), and the present review too. This pandemic, in its first stage, meant closing borders and stopping cross-border cooperation. But very soon a cross-border reality emerged, and $\mathrm{CBC}$ was on most political agendas (at least for some time): labour market, business, study, civic society, and many cross-border interactions, even in essential services, were interrupted every time that a border crossing was declared closed. Even at the external borders, but particularly within the EU, there are several million people crossing borders every day for work, for study, for whatever reason. They have growing exigences, demanding simplification of procedures, cross-border provision of public services, as well as the systematization and security of their jobs, and of business and research across the borders. These growing cross-border communities are in need of instruments for keeping the sustainability of their cooperation and guaranteeing the survival of these activities after lockdown and during reconstruction.

The first of these instruments was probably the Madrid Outline Convention of the Council of Europe from 1980. Then there was the second but probably the most important instrument, Interreg in 1990. And then, the most "revolutionary" one arrived in 2006 (better tuned in 2013). After a long process of analysis and discussion by the EU institutions and European border and cross-border regions to design a legal instrument for $\mathrm{CBC}$ within European public law, the EGTCs were born. The first regulation came into life and, up to now, almost 80 structures have been created, with different levels of competence, tasks, and types of support. They can be more or less powerful, but they can be growingly found all over Europe, and particularly in some borders. This is perhaps due to the fact that available instruments before were not sufficient. Now it seems to be a good time to make a deep review like this book is doing, from different perspectives, adding enormous value to other revisions made by the EU institutions or some individual EGTCs. I have found very interesting analyses that deserve a read for those who want to know more about the legal aspects of EGTCs, the evolving interpretation of this tool, their role in building Europe, in cross-border integration, planning, governance, etc. Please let me go now through the different chapters, with the aim of drawing your attention and perhaps to stimulating you to read some of the contributions in this book.

In the foreword, the Hungarian Minister of Justice explains the high appreciation of this instrument in her country, its added value and perspectives.

Then, in the first chapter, Dr. Marcin Krzymuski, a legal expert with a deep knowledge of the cross-border Polish-German area, explains the institutionalization of CBC through EGTCs and provides a very interesting overview of the performance, structure, funding procedures, etc. This chapter could be very inspiring for those who already have experience and want to know more, but even for those who are learning about EGTCs for the first time. They can find very useful information on how to form one, how to build it, etc. 
Gyula Ocskay, editor of the book and Secretary General of Central European Service for Cross-Border Initiatives (CESCI), proposes an interesting change in the interpretation of the EGTCs. He refers to the initial intention of the founding fathers to implement European territorial cooperation. But when we observe the situation on the ground, EGTCs are very often considered to be multipurpose or with even changing purposes, or pursue an integrated action. And they could either act as an instrument to provide a certain service, or assume the institutional representation of the cross-border area. So, at the end of the day, 15 years of EGTC-driven integration might be summarised in the will of their primary users, boosting integration with their neighbours, and looking for greater flexibility, adaptability, visibility and representation through the EGTCs.

Prof. James W. Scott, a world authority on border studies at the Karelian Institute of the University of Eastern Finland in Joensuu, explains the role of the EGTCs in the institutionalization of CBC as a more sophisticated way of cooperation. He also draws our attention to the fact that, in times of crisis, populism and growing nationalism, cross border cooperation remains a holder for the spirit of open borders and cooperation.

Sara Svenson (Halmstad University), who cooperates frequently with CESCI (see the excellent overview of the EGTCs around Hungary edited in 2016 by Ms Svenson and Mr Ocskay), highlights some of the major challenges for EGTCs after reviewing three relevant cases (SK-HU, RO-HU-RS and DK-SE borders). And she stresses that EGTCs are not an end in themselves but the facilitator of territorial cooperation and integration.

Frédéric Durand and Antoine Decovill, researchers at the Luxembourg Institute of SocioEconomic Research (LISER), warn that EGTCs do not seem to have been used to their full potential yet, especially in terms of cross-border integration. And there are different reasons for that. They are quite critical, and probably they have touched some of the "hot potatoes" here. Sometimes EGTCs could be created in an opportunistic way, just to get Interreg funding or to secure jobs. Or as a discussion forum for other issues, but not for strengthening cross-border cooperation, which should be its main purpose. Perhaps here we can see a lack of political will. And the other way round: when there is political will, we can see that $\mathrm{CBC}$ operates well, whether through EGTCs, through euroregions or whatever. Of course, EGTCs make it possible to do more things.

Next comes a very interesting overview by Mátyás Jaschitz, Director of CESCI, on the role of $\mathrm{CBC}$ in spatial planning. Actually, everything started for $\mathrm{CBC}$ with the planners, when they voiced that it was not possible to progress in European integration without planning across national boundaries and without some minimum common standards. So, it is very interesting going at the very start of the issue.

Prof. Eduardo Medeiros, another well-known researcher on cross-border issues at the University of Lisbon (see its work on Cross-Border Impact Assessment, or on "covidfencing effects" together with other authors in this book), explains the EGTCs as a tool for cross-border multilevel governance, which is another very interesting point. They are not an El Dorado for CBC and could become "fast food" EU policy tool due to their immediateness.

Peter Ulrich, researcher at the European University Viadrina in Frankfurt (Oder), writes about the power of EGTCs to provide participatory governance, analysing four practical cases (three operational EGTCs: Galicia-Norte de Portugal, South Tyrol-Tyrol-Trentino, and StrasbourgOrtenau; and one under construction: TransOderana) and announcing a deeper publication very soon (already published in Nomos in 2021). He also discusses the social dimension of EGTCs and $\mathrm{CBC}$, and the relevance of the active participation of the civil society, the provision of social services, and social innovation in cross border regions that can be implemented through the EGTCs.

Alice Engl, researcher at EURAC, writes from the perspective of minority studies about the role of minorities in cross-border cooperation. She distinguishes between legal, political, and socioeconomic layers of CBC in multi-ethnic and multi-cultural contexts.

Jean Peyrony, the Director General of the Mission Opérationnelle Transfrontalière (MOT), discusses "competences or just tasks for EGTCs?" He talks about the re-activation of this debate 
during the negotiation of the the Aachen Treaty, and the relevance at the light of the role of borders and $\mathrm{CBC}$ during the present pandemic.

Estelle Evrard, researcher at the University of Luxembourg, fosters "spatial justice" in EU borderlands, and she explains how former front lines have been converted into interfaces and laboratories for European integration. So, good CBC could add enormous value, and a very sustainable value, to the EU integration process, beyond borderlands.

As you can see, there is a lot of food for thought in this publication, a really interesting set of readings that I would recommend you browse through whether you are a practitioner, a scholar, or just someone interested in this very particular tool for European integration. 